\title{
Utilization of sweet sorghum bagasse and citric acid for manufacturing of particleboard II: influences of pressing temperature and time on particleboard properties
}

\author{
Sukma Surya Kusumah ${ }^{1,2}$ (1) Kenji Umemura ${ }^{1}$ Ikhsan Guswenrivo ${ }^{2,3}$ • \\ Tsuyoshi Yoshimura $^{3} \cdot$ Kozo Kanayama $^{1}$
}

Received: 12 August 2016 / Accepted: 14 December 2016 / Published online: 17 January 2017

(C) The Japan Wood Research Society 2017

\begin{abstract}
Development of environmentally friendly particleboard made from sweet sorghum bagasse and citric acid has recently attracted attention. In this study, we investigated the effects of pressing temperature and time on physical properties, such as dry bending (DB), internal bond strength (IB), and thickness swelling (TS) of particleboard. Wet bending (WB), screw-holding power (SH), biological durability, and formaldehyde emission of particleboard manufactured under effective pressing temperature and time were also evaluated. Particleboards bonded with phenol formaldehyde (PF) resin and polymeric 4,4'-methylenediphenyl isocyanate (pMDI) were manufactured as references. Effective pressing temperature and time were $200^{\circ} \mathrm{C}$ and $10 \mathrm{~min}$, respectively. It was clarified that DB, IB, and TS satisfied the type 18 requirements of the JIS A 5908 (2003), and were comparable to those of particleboard bonded with PF and pMDI. The WB and SH of particleboard did not satisfy type 18 of JIS. Particleboard manufactured under effective pressing conditions had good biological durability and low formaldehyde emission. Based on the results of infrared spectra measurement, the degree of ester linkages increased with increased pressing temperature and time.
\end{abstract}

Sukma Surya Kusumah

Sukma_kusumah@rish.kyoto-u.ac.jp

1 Laboratory of Sustainable Materials, Research Institute for Sustainable Humanosphere, Kyoto University, Gokasho, Uji, Kyoto 611-0011, Japan

2 Research Center for Biomaterial, Indonesian Institute of Sciences (LIPI), Jl. Bogor KM 46, Cibinong, Bogor 1691, Indonesia

3 Laboratory of Innovative Humano-habitability, Research Institute for Sustainable Humanosphere, Kyoto University, Gokasho, Uji, Kyoto 611-0011, Japan
Keywords Citric acid · Particleboard · Pressing temperature and time $\cdot$ Sweet sorghum bagasse

\section{Introduction}

The demand for wood-based composite products has increased substantially around the world with the increase in population [1]. Particleboard is a wood-based composite product that accounts for $29 \%$ of the total production of wood-based composite products, and is growing at $2-4 \%$ annually [2]. Nevertheless, because of the declining potential of forests [3], it may not be possible to meet the gradually increasing needs for particleboard in the future. Consequently, alternative lignocellulose material could play a substantial role in the manufacture of particleboard. Using non-wood lignocellulose, such as agricultural waste as the raw material for particleboard, has been researched on a wide variety of materials.

Currently, sweet sorghum (Sorghum bicolor L. Monech) is widely cultivated throughout the world for utilization as a biofuel, food, and feed. Nowadays, the world production of sorghum is 65.03 million metric tons in this year and will be increase about 0.26 million metric tons in the next year [4]. In Indonesia, it is a common multi-purpose crop [5]. Large quantities of sweet sorghum bagasse have conventionally been used as a raw material for silage [6] and bio-pellets [5]. However, the utilization of sweet sorghum bagasse is ineffective in terms of carbon reserves due to the short-term nature of its consumption. One method for resolving this problem is to utilize sweet sorghum bagasse as a raw material for producing particleboard.

On the other hand, particleboard ordinarily uses a synthetic resin as an adhesive. Synthetic resins are composed of assorted chemical substances derived from fossil 
resources. Utilization of such resins will almost certainly be restricted in the future, due to decreases in the reserves of fossil resources. Hence, the development of natural adhesive using bioresources [7] (i.e., lignin, tannin, proteins, polysaccharides, and ligno-cellulose nanofiber (LCNF) [8]), has been investigated. Nevertheless, the use of chemical substances derived from fossil resources and toxic chemical substances was needed to obtain good bondability [9-12] with such natural adhesives. Therefore, further research is urgently needed to obtain excellent bonding performance with natural adhesives that do not rely on either fossil resources or toxic chemical substances.

Recently, Umemura et al. [13] found that citric acid has good adhesivity for wood and elucidated the physical properties of particleboard bonded with citric acid $[14,15]$. Particleboard bonded with citric acid using bamboo [16] or bagasse [17] has also been evaluated and was found to have good physical properties.

In our previous report, we found that low moisture content $(10 \%)$ of sprayed adhesive particles before pressing and citric acid content of $20 \mathrm{wt} \%$ resulted in particleboard with good physical properties [18]. However, effective pressing temperature and time, biological durability, and formaldehyde emission of particleboard are not yet known. In the present study, we investigated the effects of pressing time and temperature on the physical properties of particleboards. Furthermore, wet bending (WB), screw-holding power $(\mathrm{SH})$, biological durability, and formaldehyde emission of particleboard under effective pressing temperature and time were evaluated.

\section{Materials and methods}

\section{Preparation of materials}

Sweet sorghum (Sorghum bicolor L. Monech) bagasse (SSB) was provided by the Center for Innovation of the Indonesian Institute of Sciences, in Indonesia. The particles were produced using a chipper and knife-ring flaker machines. The particles were screened, and those that remained between aperture sizes of $0.9-5.9 \mathrm{~mm}$ were used as a raw material. The particles were dried in an oven at $80^{\circ} \mathrm{C}$ for $12 \mathrm{~h}$, at which point the moisture content of particles was less than $4 \%$. An extra purity grade of citric acid (anhydrous) was purchased from Nacalai Tesque, Inc. (Kyoto, Japan) and was used without further purification. Citric acid was dissolved in water at a concentration of $59 \mathrm{wt} \%$, and the solution was used as the adhesive. The $\mathrm{pH}$ and viscosity of the adhesive at $20^{\circ} \mathrm{C}$ were 0.3 and $30 \mathrm{mPa}$ s, respectively. Phenol formaldehyde (PF) (B-1370 type) resin and polymeric 4,4'-methylenediphenyl isocyanate (pMDI) (B-1605 type) from Oshika Co., Ltd. (Tokyo, Japan) were used as reference adhesives.

\section{Manufacture of particleboards}

Based on the results of the previous paper [18], $20 \mathrm{wt} \%$ citric acid (CA) was sprayed onto particles and then dried at $80^{\circ} \mathrm{C}$ for $12 \mathrm{~h}$ to reach a moisture content of about $10 \%$. Subsequently, the particles were formed into mats using a $300 \times 300 \mathrm{~mm}$ forming box. The mat of particles was pressed using a hot-pressing machine under various temperature and time conditions, i.e., $140-220^{\circ} \mathrm{C}$ and 2-15 min, respectively. Particleboard size and target density were $300 \times 300 \times 9 \mathrm{~mm}$ and $0.8 \mathrm{~g} / \mathrm{cm}^{3}$, respectively. Particleboard thickness was controlled by a 9 -mm-thick metal bar during the hot-pressing process. In addition, each particleboard was bonded using 12-wt\% PF resin, and 8 -wt $\%$ content pMDI was manufactured as a reference. Both the PF resin and pMDI were diluted by acetone of 20 and $10 \mathrm{wt} \%$, respectively, to reduce the viscosity of these adhesives. The particles were used to manufacture the particleboard bonded with PF and pMDI without drying after spraying with adhesive. The mat moisture contents of both particleboard bonded with PF and pMDI before pressing were about 20 and $6 \%$, respectively. The size and target density of each of these boards was similar to those of the particleboards bonded with CA. Based on our previous research [18], particleboard bonded with $\mathrm{PF}$ and pMDI was manufactured at $200^{\circ} \mathrm{C}$ for $6 \mathrm{~min}$ and $180^{\circ} \mathrm{C}$ for $8 \mathrm{~min}$, respectively.

\section{Evaluation of the properties of the particleboards}

\section{Physical properties}

Particleboard was tested according to the Japanese industrial standards for particleboards (JIS A 5908, 2003) [19], after being conditioned for 1 week at a room temperature of $20^{\circ} \mathrm{C}$ and a relative humidity of approximately $60 \%$. Each small specimen of physical properties testing was cut from the fabricated particleboard $(300 \times 300 \times 9 \mathrm{~mm})$ using circular saw. The specimen was taken from each position of particleboard cross section (i.e., edge and center position) as a representation of data. The dry-bending strength of particleboards, i.e., the modulus of rupture (MOR) and the modulus of elasticity (MOE), was evaluated by conducting a three-point bending test on a $200 \times 30 \times 9 \mathrm{~mm}$ specimen of each board under dry conditions. The loading speed and effective span were $10 \mathrm{~mm} / \mathrm{min}$ and $150 \mathrm{~mm}$, respectively. The internal bonding (IB) strength was investigated using a $50 \times 50 \times 9 \mathrm{~mm}$ specimen of each board, and the loading speed was $2 \mathrm{~mm} / \mathrm{min}$. The thickness swelling (TS) and water absorption (WA) values of each board after water 
immersion at $20^{\circ} \mathrm{C}$ for $24 \mathrm{~h}$ were measured for specimens of the same size as those used for the IB test.

Subsequently, bending strength test B under wet conditions and screw-holding ( $\mathrm{SH}$ ) power test of particleboard under the effective condition of hot-pressing temperature and time were also evaluated according to JIS A 5908 [19]. The size of wet-bending strength specimen is as same as dry-bending strength. The SH specimen of $50 \times 100 \mathrm{~mm}$ was drilled by drill of $2 \mathrm{~mm}$ in diameter to make holes of about $3 \mathrm{~mm}$ deep in the two center positions of board cross section. The distance of each hole was $25 \mathrm{~mm}$ from the edge side as a mentioned in JIS A 5908 [19]. Screws used for SH test were $2.7 \mathrm{~mm}$ in diameter and $16 \mathrm{~mm}$ in length. The screws were inserted into the hole to a depth of $9 \mathrm{~mm}$, leaving $7 \mathrm{~mm}$ of shank free for loading grip. The depth of inserting screw into the hole is modification method of JIS that the requirement of the screw depth is approximately $11 \mathrm{~mm}$. The pulling-out load speed was about $2 \mathrm{~mm} / \mathrm{min}$.

Each experiment was performed in five replications, and the average values and standard deviations were calculated. The MOR, MOE, and IB values of particleboards shown in the figures are values that were corrected for each target density based on regression lines between the actual values of the mechanical properties and the specimen densities.

\section{Termite and decay resistance}

Termite and decay resistance of particleboard manufactured under effective pressing condition, and each particleboard bonded with PF and pMDI was evaluated. The size of specimens for each test of termite and decay resistance was $20 \times 20 \times 9 \mathrm{~mm}$. Five specimens per board type, such as particleboard bonded using $\mathrm{CA}, \mathrm{PF}$, and pMDI, were assayed against termites and decays.

In the termite resistance test, the specimens were exposed to the subterranean termite Coptotermes formosanus Shiraki, according to the Japan Wood Preserving Association (JWPA) standard JWPS-TW-P.1 (2001) [20]. The containers used for the termite test were acrylic cylinders $(80 \mathrm{~mm}$ in diameter and $60 \mathrm{~mm}$ in height), the lower ends of which were sealed with a 5-mm-thick hard dental plaster (New Plastone, GC Corp.). Test specimen was set at the center of the plaster bottom of the test container. A total of 150 worker termites and 15 soldiers collected from a laboratory termite colony at Research Institute for Sustainable Humanosphere (RISH), Kyoto University, were introduced into each test container. Small wood blocks $(20 \times 20 \times 9 \mathrm{~mm})$ of sugi (Cryptomeria japonica) were used as a control. The assembled containers were placed on damp cotton pads to supply water to the specimens, and left at $28^{\circ} \mathrm{C}$ and $>85 \%$ relative humidity (RH) in darkness for 3 weeks. The mass loss of the specimens as a result of termite attack was calculated based on the difference between the initial and final oven-dry weights of the specimens after cleaning off the debris from termite attack.

In the decay resistance tests, a monoculture decay test was carried out with the brown-rot fungus [Fomitopsis palustris (Berk. Et Curt) Gilbn. \& Ryv. (FFPRI 0507)] and the white-rot fungus [Trametes versicolor (L.:Fr.) Pilat. (FFPRI 1030)], according to the JIS K 1571 standard method (2004) [21]. A 100-ml aliquot of liquid medium containing $1.5 \%$ malt extract, $0.3 \%$ peptone, and $4 \%$ glucose was inoculated with stock culture of either T. versicolor or F. palustris. The incubation of inoculated liquid medium was conducted with a shaker $(120 \mathrm{rpm})$ at $26^{\circ} \mathrm{C}$ for 10 days. A 250 -g medium of sea sand in a glass jar was permeated with $80-85 \mathrm{ml}$ of nutrient solution containing $4 \%$ glucose, $0.3 \%$ peptone, and $1.5 \%$ malt extract for T. versicolor; half as much of each component was used for F. palustris. About 3-4 $\mathrm{ml}$ of these liquid fungal stock cultures were used in inoculating the jars. The oven-dry weight of board specimens was measured, and specimens were then sterilized with gaseous ethylene oxide. When the mycelium had fully covered the medium in the glass jars, three specimens were placed on top of the growing mycelium. A plastic mesh spacer was used for $F$. palustris, but not for T. versicolor. Small wood blocks $(20 \times 20 \times 9 \mathrm{~mm})$ of sugi wood (Cryptomeria japonica) were used as a control. The test jars were then incubated at $27^{\circ} \mathrm{C}$ and for 12 weeks. Nine replicates were tested for each decay fungus for each board type. The extent of the fungal attack was expressed as the average mass loss (percent) calculated from oven-dry weights of nine specimens before and after the decay procedure.

\section{Formaldehyde emission}

The formaldehyde emission of $150 \times 50 \mathrm{~mm}$ specimens was measured by desiccator method outlined in the JIS A 1460 (2001) [22]. Ten replicates were tested, for a total surface board area of approximately $1800 \mathrm{~cm}^{2}$. The specimens were placed in a desiccator containing a vessel with water. The formaldehyde released from the specimens at $20^{\circ} \mathrm{C}$ over $24 \mathrm{~h}$ was absorbed by the water solution. This solution was first thoroughly mixed before measurement. Detail procedures of formaldehyde emission measurement in the JIS A 1460 [22] had been obeyed. The absorbance of formaldehyde emission in the water solution was measured at $412 \mathrm{~nm}$ of wavelength against water as a control using a spectrophotometer.

The slope of the calibration curve on the standard solution of formaldehyde was carried out by measuring the wavelength absorbance of the formaldehyde standard solution using a spectrophotometer with various quantities of formaldehyde standard solution (i.e., $0-3 \mathrm{mg}$ ). The graphs of the correlation between the quantity of formaldehyde 
and the absorbance was then determined to obtain the slope by the least squares regression line method. The concentration of formaldehyde from the test piece absorbed into the water in the glass crystallizing dish inside the desiccator was calculated using the following the formula from the JIS A 1460 [22]:

$G=F \times\left(A_{\mathrm{d}}-A_{\mathrm{b}}\right) \times(1800 / S)$

where $G$ : concentration of formaldehyde from the test piece $(\mathrm{mg} / \mathrm{l}) . A_{\mathrm{d}}$ : absorbance of solution inside desiccator containing the test piece. $A_{\mathrm{b}}$ : absorbance of background formaldehyde (blank test). $F$ : slope of the calibration curve of the standard formaldehyde solution $(\mathrm{mg} / \mathrm{l})$. $S$ : surface area of test piece $\left(\mathrm{cm}^{2}\right)$.

\section{Mat temperature measurement}

The temperature of mat during hot pressing was measured with a thermocouple sensor (Type T/copper-constantan) and a data logger (HIOKI 8420-51 memory Hi Logger). The thermocouple sensor was installed at each layer of mat (i.e., face, core, and back layer) and connected to the data logger. Measurement of the change in mat temperature was initiated when the platen pressure reaches the mat surface.

\section{Fourier transform infrared spectroscopy (FTIR)}

The edge of a specimen that had undergone the cyclic aging treatment (i.e., water immersion at 20 and $70^{\circ} \mathrm{C}$ for $24 \mathrm{~h}$; drying at $105^{\circ} \mathrm{C}$ for $10 \mathrm{~h}$; and water boiling treatment for $4 \mathrm{~h})$ was scratched to obtain small particles. The particles were ground into a powder, and the powder was dried in a vacuum-drying oven at $60^{\circ} \mathrm{C}$ for $12 \mathrm{~h}$. All Infrared spectra were observed with an FTIR spectrophotometer (FT/ IR-4200; JASCO Corporation) using the KBr disk method, and recorded with an average of 16 scans at a resolution of $4 \mathrm{~cm}^{-1}$. As a control, the infrared spectra of sweet sorghum bagasse particles were also measured.

\section{Results and discussion}

\section{Effect of pressing temperature}

The influence of pressing temperature on the physical properties of particleboard was observed under a pressing time of $10 \mathrm{~min}$. Figure 1 shows the relationship between the pressing temperature and the bending properties of the particleboard. Bending properties increased together with pressing temperature from 140 to $200^{\circ} \mathrm{C}$, and then decreased at $220^{\circ} \mathrm{C}$. This indicated that a pressing temperature of $200^{\circ} \mathrm{C}$ is the effective temperature in terms of bending properties in this study. Decreasing of

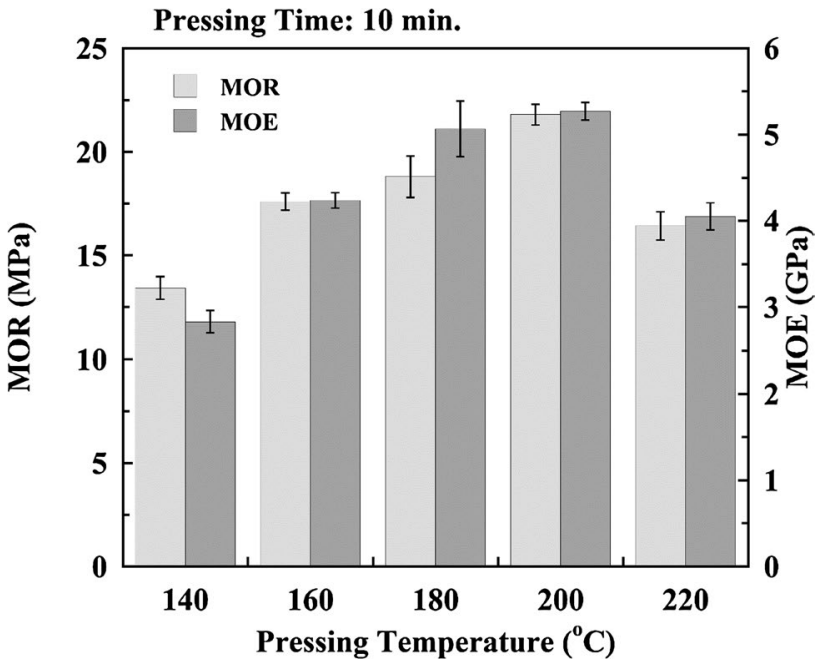

Fig. 1 Relationship between pressing temperature and bending properties of particleboards bonded with $20 \mathrm{wt} \%$ citric acid content. Error bar indicates the standard deviation. A number of replications are 5 $(n=5)$

the bending properties at $220^{\circ} \mathrm{C}$ might be due to material degradation and lead to embrittlement of surface layer [23]. Actually, chemical component of lignocellulose material, including sweet sorghum bagasse, such as hemicellulose, decomposes at $220-315^{\circ} \mathrm{C}$ [24] and citric acid degrade around over $220^{\circ} \mathrm{C}$ [25]. The maximum average MOR and MOE values of particleboards were 21.8 and $5.3 \mathrm{GPa}$ at $200{ }^{\circ} \mathrm{C}$ pressing temperature, respectively. Those values were about 1.5 times or more high than those of board manufactured at $140^{\circ} \mathrm{C}$. The MOR value of particleboards manufactured at 180 and $200^{\circ} \mathrm{C}$ was higher than the requirement values in the JIS A 5908, 18-type standard [19].

Table 1 shows MOR, MOE, SH power, and formaldehyde emission of particleboard bonded with $\mathrm{CA}$ under effective hot pressing condition (i.e., $200^{\circ} \mathrm{C}$ of pressing temperature and $10 \mathrm{~min}$ of pressing time) and for particleboards bonded with PF resin and pMDI. As can be seen in the table, MOR (21.8 MPa) of the board bonded with CA was lower than those of boards bonded with PF (32.9 MPa) and pMDI (34.1 MPa), while the MOE (5.2 GPa) of the CA boards was higher with that of those bonded with synthetic resins (PF [4.5 GPa]; pMDI [4.6 GPa]). An analysis of variance (ANOVA), however, found that those values were not significantly different $(p<0.05)$. In a previous report, Azeredo et al. [26] reported that the tensile strength of wheat straw hemicellulose film decreased and its modulus of elasticity increased as the CA content increased up to $20 \mathrm{wt} \%$, due to the citric acid acting as a flexible cross linker. Based on those findings, our results might have also been caused by the citric acid acting as cross-linking agent. The acid causes the material to seem stiff and brittle; 
Table 1 MOR, MOE, screw holding (SH), IB, TS, and formaldeyde emission of sweet sorghum bagasse particleboard bonded with citric acid, $\mathrm{PF}$, and $\mathrm{pMDI}$

\begin{tabular}{|c|c|c|c|c|c|c|c|c|}
\hline \multirow{2}{*}{$\begin{array}{l}\text { Particle- } \\
\text { board Type }\end{array}$} & \multicolumn{2}{|l|}{ MOR (MPa) } & \multicolumn{2}{|c|}{$\operatorname{MOE}(\mathrm{GPa})$} & \multirow[t]{2}{*}{ IB (MPa) } & \multirow[t]{2}{*}{$\mathrm{TS}(\%)$} & \multirow[t]{2}{*}{$\mathrm{SH}(\mathrm{N})$} & \multirow{2}{*}{$\begin{array}{l}\text { Formaldehyde } \\
\text { emission } \\
(\mathrm{mg} / \mathrm{L})\end{array}$} \\
\hline & Dry test & Wet test & Dry test & Wet test & & & & \\
\hline $\mathrm{CA}$ & $21.8(0.39)$ & $7.7(0.39)$ & $5.2(0.19)$ & $1.8(0.10)$ & $0.89(0.01)$ & $10.1(2.89)$ & 348 (10.96) & $0.00(0.0000)$ \\
\hline $\mathrm{PF}$ & $32.9(1.38)$ & $14.6(1.19)$ & $4.5(0.13)$ & $1.4(0.00)$ & $0.78(0.03)$ & $20.6(2.89)$ & $652(37.16)$ & $0.01(0.0004)$ \\
\hline pMDI & $34.1(1.80)$ & $11.3(0.34)$ & $4.6(0.06)$ & $1.6(0.10)$ & $1.33(0.09)$ & $23.1(1.65)$ & $858(54.78)$ & $0.00(0.0000)$ \\
\hline
\end{tabular}

Values in parentheses are standard deviation

Citric acid (CA) is particleboard bonded with $20 \mathrm{wt} \%$ citric acid content in optimum of pressing temperature $\left(200^{\circ} \mathrm{C}\right)$ and time $(10 \mathrm{~min})$; phenol formaldehyde (PF) is particleboard bonded with $12 \mathrm{wt} \% \mathrm{PF}$ resin with the pressing condition of $200^{\circ} \mathrm{C}$ for 6 min; polymeric $4,4^{\prime}$-methylenediphenyl isocyanate (pMDI) is particleboard bonded with $8 \mathrm{wt} \%$ pMDI with the pressing condition of $180^{\circ} \mathrm{C}$ for 8 min; modulus of rupture (MOR) and modulus of elasticity (MOE) are bending properties of particleboard; internal bond (IB) is internal bonding strength of particleboard; thickness swelling (TS) is swelling of thickness of particleboard after imersion of sample in the $20^{\circ} \mathrm{C}$ of water for $24 \mathrm{~h}$; screw holding $(\mathrm{SH})$ is screw-holding power of particleboard

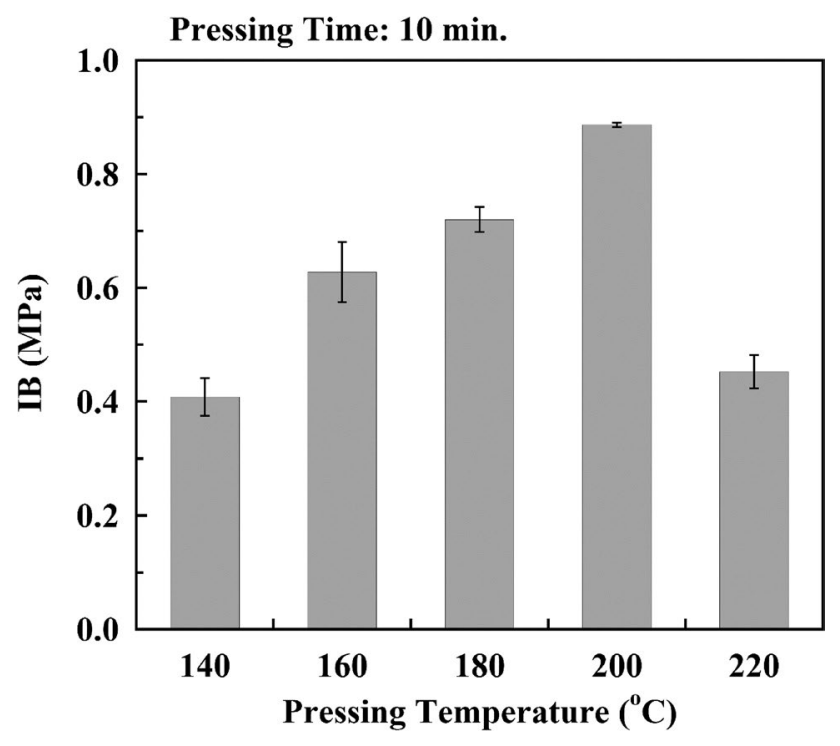

Fig. 2 Relationship between pressing temperature and IB strength of particleboards bonded with 20 wt $\%$ citric acid content. Error bar indicates the standard deviation. A number of replications are 5 $(n=5)$

hence, the elasticity was improved and the strength of particleboard decreased.

Figure 2 shows the relationship between the pressing temperature and the IB strength of particleboards. IB strength increased gradually when boards were manufactured at $140-200^{\circ} \mathrm{C}$, while it decreased sharply in those manufactured at $220^{\circ} \mathrm{C}$. The IB value of the board manufactured at $200^{\circ} \mathrm{C}$ was double that of boards manufactured at 140 and $220^{\circ} \mathrm{C}$. Theoretically, the IB strength is affected by the adhesiveness of the core layer [27]. According to this general theory and the melting point of $\mathrm{CA}\left(\sim 150^{\circ} \mathrm{C}\right)$, the board manufactured at $200^{\circ} \mathrm{C}$ might have reached an effective temperature of more than $150^{\circ} \mathrm{C}$ in the core layer during hot pressing. Hence, the citric acid melted, and could have easily created linkages with the sweet sorghum bagasse component to obtain good adhesiveness.

On the other hand, the IB strength of the board decreased at a higher pressing temperature of $220^{\circ} \mathrm{C}$. A previous study by Yang et al. [24] found that the hemicellulose decomposed at $220-315^{\circ} \mathrm{C}$. In addition, the added $\mathrm{CA}$ as acid compound would be promote the degradation of hemicellulose [17]. According to those studies, the decreasing of IB strength at that temperature appeared to have been caused by the degradation and decomposition of sweet sorghum bagasse components, such as hemicellulose. The formation of its volatile components then proceeded, and as a result, these components interfered with the adhesiveness of the core layer. This means that a pressing temperature of $200^{\circ} \mathrm{C}$ was likely the effective temperature for obtaining good IB strength. Furthermore, all the boards met the type 18 standard of the JIS A 5908 [19]. In addition, the IB value of the board under effective pressing temperature as shown in Table 1 was higher than that of those bonded with PF resin and lower than that of boards bonded with pMDI.

Figure 3 shows the TS and WA of particleboards manufactured at different pressing temperatures. TS and WA values declined considerably up to $200^{\circ} \mathrm{C}$, and then decreased slightly. The TS of boards manufactured at high-pressing temperatures of 200 and $220^{\circ} \mathrm{C}$ satisfied the requirement $(<12 \%)$ of the type 18 standard of JIS A 5908 [19]. Furthermore, the TS of those boards was lower than that of boards bonded using PF and pMDI, as shown in Table 1 . This means that the CA boards manufactured at 200 and $220^{\circ} \mathrm{C}$ had good dimensional stability. Previous research has reported that the cross-linking between $\mathrm{CA}$ and wood particles at higher pressing temperatures of 200 and $220^{\circ} \mathrm{C}$ might occur at a higher rate than at temperatures less than $180^{\circ} \mathrm{C}$ [28]. Hence, cross-linking between CA and sweet sorghum bagasse particles would also be improved. 


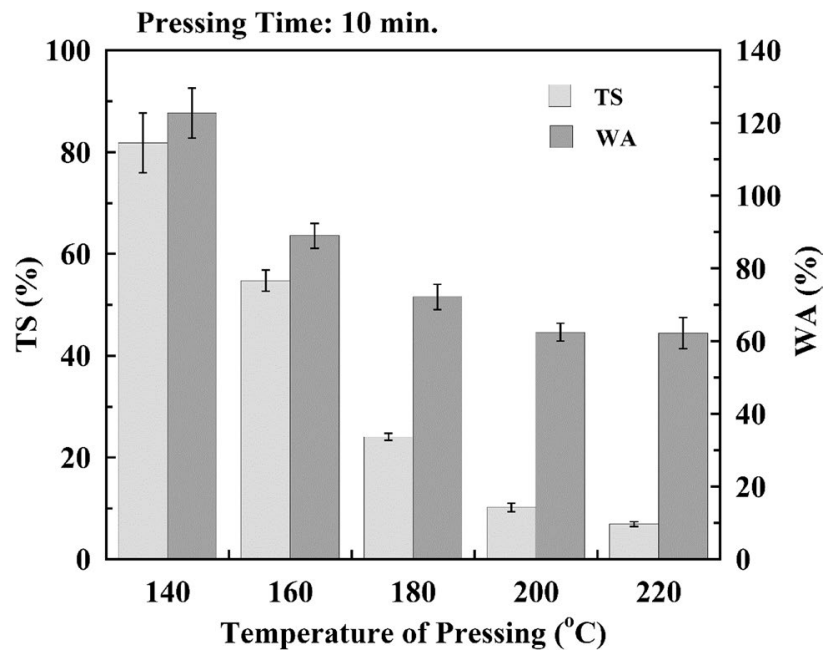

Fig. 3 Effect of pressing temperature on TS and WA of particleboards bonded with $20 \mathrm{wt} \%$ citric acid content. Error bar indicates the standard deviation. A number of replications are $5(n=5)$

$\mathrm{Xu}$ et al. [29] pointed out that sugarcane bagasse is composed of sucrose-rich pith and a lignocellulose rind, as well as quantitative non-fiber substances that give sugarcane bagasse particleboard bonded with Urea Formaldehyde (UF), PF or pMDI a large water-absorbing property. Hosseinaei et al. [30] reported that the high hemicellulose of wood flour affected the water absorption of composite board. Considering those studies, we hypothesized that the high hemicellulose content of sweet sorghum bagasse [18] might have affected the high TS of boards bonded with PF and pMDI. Accordingly, a pressing temperature of $200^{\circ} \mathrm{C}$ or higher was necessary to obtain good dimensional stability. Based on the results shown in Figs. 1, 2, and 3, it we determined that the effective pressing temperature of particleboard manufactured from sweet sorghum bagasse and CA was $200^{\circ} \mathrm{C}$.

\section{Effect of pressing time}

The effects of pressing time on physical properties of particleboard were investigated under a pressing temperature of $200^{\circ} \mathrm{C}$. Figure 4 shows the bending properties of particleboard with different pressing times. The MOR and MOE increased gradually from 2 to $10 \mathrm{~min}$ and then decreased slightly at $15 \mathrm{~min}$. This means that $10 \mathrm{~min}$ is an effective pressing time to obtain good bending properties. The reason for the slight decrease of the bending properties at 15 min due to degradation of material and adhesive. Except for the board manufactured at $2 \mathrm{~min}$, all the boards had bending strength satisfied the type 18 requirements of JIS A 5908 [19].

Relationship between the IB strength and pressing time is shown in Fig. 5. The IB strength of the boards increased

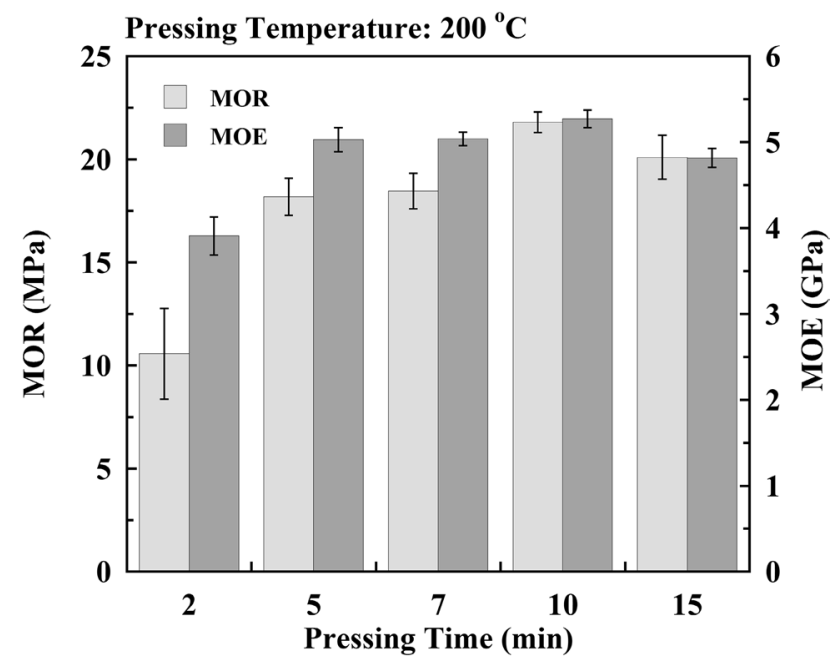

Fig. 4 Relationship between pressing time and bending properties of particleboards bonded with $20 \mathrm{wt} \%$ citric acid content. Error bar indicates the standard deviation. A number of replications are 5 $(n=5)$

greatly with increasing of pressing time from 2 to $10 \mathrm{~min}$ and then decreased slightly at $15 \mathrm{~min}$. The IB value of the board with 2 min pressing time was extremely lower value. Based on the temperature of each layer of the board during hot pressing, as shown in Fig. 6, the increasing temperature in the core layer of particleboard was slower than that in the surface layers. The temperature at core layer for $2 \mathrm{~min}$ pressing reached less than target temperature of $200^{\circ} \mathrm{C}$, i.e., around $150{ }^{\circ} \mathrm{C}$; hence, the citric acid did not react properly at core layer. Consequently, the adhesiveness at core

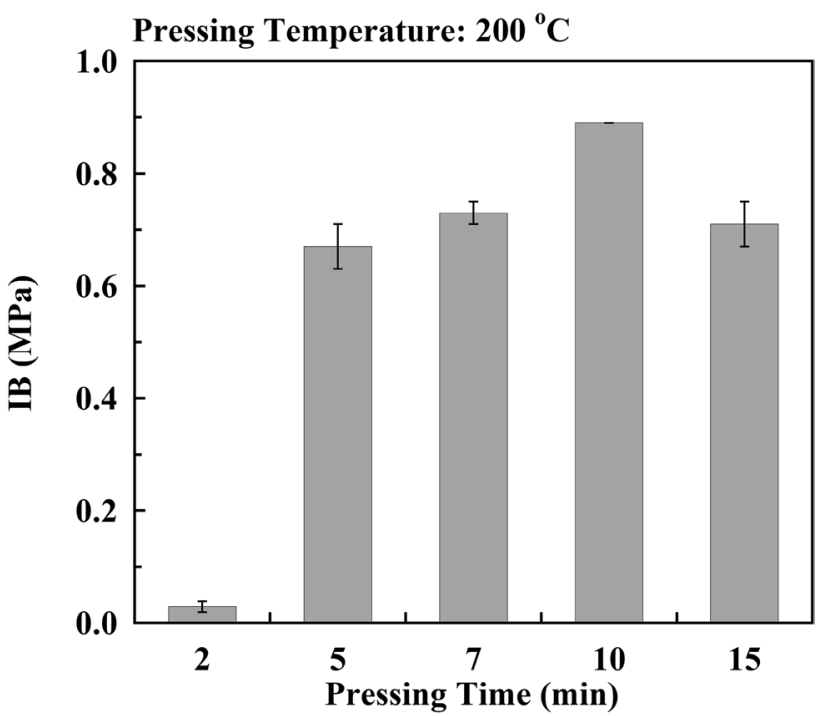

Fig. 5 Relationship between pressing time and IB strength of particleboards bonded with $20 \mathrm{wt} \%$ citric acid content. Error bar indicates the standard deviation. A number of replications are $5(n=5)$ 


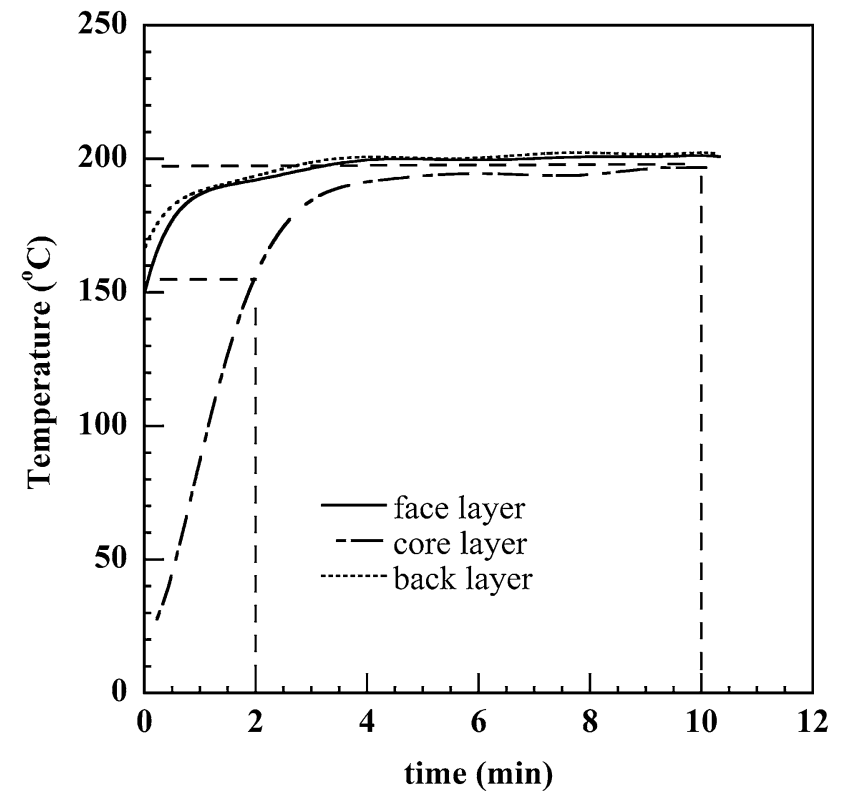

Fig. 6 Temperature of each layer of particleboard during hot pressing

layer was poorly. However, the temperature at core layer for pressing time more than $5 \mathrm{~min}$ was closed to the target temperature and reached about $200^{\circ} \mathrm{C}$ at $10 \mathrm{~min}$. Because of that, the IB strength of the board increased significantly from 2 to $5 \mathrm{~min}$ and then increased gradually until $10 \mathrm{~min}$. It means that the pressing time of $10 \mathrm{~min}$ was needed to obtain good adhesiveness in all layer of particleboard. Furthermore, excluding the board manufactured for $2 \mathrm{~min}$, all the boards had higher IB strength than the type 18 requirement of JIS A 5908 [19].

Figure 7 shows the effect of pressing time on TS and WA of particleboard. The board with 2 min pressing time had the highest TS and WA values and then decreased sharply at 5 min pressing time followed with slight decreasing of those values at 5-15 min. TS values of the board with 10 and 15 min pressing time were 10.2 and $9.5 \%$, respectively. Those values were not significantly different $(p<0.05)$ and were about one-five lower than TS of the board with 2 min pressing time. The TS values of the boards with $10 \mathrm{~min}$ pressing time or longer satisfied the requirement type 18 $(<12 \%)$ of JIS A 5908 [19]. Therefore, the pressing time of $10 \mathrm{~min}$ or longer was required to attain good dimensional stability of the board.

\section{Other properties of particleboard under effective condition of particleboard manufacturing}

Based on the results above, we clarified the effective pressing temperature of $200^{\circ} \mathrm{C}$ and pressing time of $10 \mathrm{~min}$. Moreover, in our previous research result, we found the effective pre-drying treatment of particle before hot

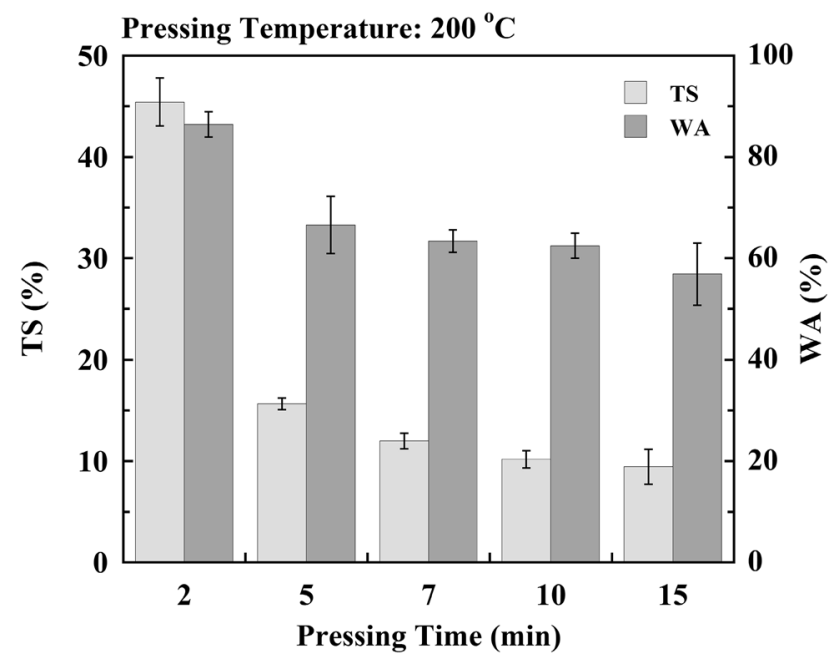

Fig. 7 Effect of pressing time on TS and WA of particleboards bonded with $20 \mathrm{wt} \%$ citric acid content. Error bar indicates the standard deviation. A number of replications are $5(n=5)$

pressing and citric acid content of $20 \mathrm{wt} \%$. According to those effective manufacturing condition, bending strength under wet condition, SH power, formaldehyde emission, the resistance of termite, and decay was investigated. Considering further application of the particleboard (i.e., exterior or interior) for construction material, the information of those particleboard properties was necessary.

The results are shown in Table 1. As with dry-bending strength, the wet-MOR of CA boards was lower than that of boards bonded with PF and pMDI. However, the wet-MOE of boards was higher than those of boards bonded with PF and pMDI. The wet-MOR value of the board under effective conditions satisfied the type 13 requirement of JIS A 5908 (>6.5 MPa) [19]. SH of the board was lower than that of boards bonded with PF and pMDI, probably because the CA made particles brittle [31]. Gambhir and Jamwal [32] reported that brittle particles absorbed very little energy. This means that boards bonded with CA seemed to result in weak holding power for screws. The $\mathrm{SH}$ value of the board bonded with CA satisfied type 8 standard of JIS A 5908 (>300 N) [19]. As to the formaldehyde emission test, the board bonded with CA did not emit formaldehyde, such as the boards bonded with pMDI and PF. The formaldehyde emission value of the board bonded with CA was lower than the $\mathrm{F}^{* * * *}$ criteria of the lowest formaldehyde emission of JIS A 5908 standard [19]. Thus, boards bonded with CA are environmentally friendly.

The mass losses in the specimens by termite attack are shown in Table 2. The board bonded with CA contributed to higher termite mortality and a lower degree of mass loss than the controls, and was almost similar to those bonded with PF and pMDI. This indicated that chemicals derived from CA probably show inhibitory 
Table 2 Termite and decay resistance of sweet sorghum bagasse particleboard bonded with citric acid, PF, and pMDI

\begin{tabular}{lclrl}
\hline Biological-durability testing & \multicolumn{2}{l}{ Specimen type } & & \\
\cline { 2 - 5 } & CA & PF & pMDI & Control \\
\hline Termite resistance & & & \\
$\quad$ Termite mortality (\%) & $42.8(4.1)$ & $46.4(9.4)$ & $37.9(2.1)$ & $24.73(5.84)$ \\
Mass loss (\%) & $5.9(0.36)$ & $3.92(0.28)$ & $5.91(0.9)$ & $13.57(2.35)$ \\
Decay resistance & & & \\
Mass loss of the specimen expose to & $5.34(1.36)$ & $5.79(2.83)$ & $4.54(0.63)$ & $10.23(4.77)$ \\
$\quad$ Brown-rot fungus (\%) & $21.63(11.72)$ & $9.09(0.78)$ & $31.02(5.41)$ & $37.49(6.05)$ \\
White-rot fungus (\%) & & & &
\end{tabular}

Values in parentheses are standard deviation

Citric acid (CA) is particleboard bonded with $20 \mathrm{wt} \%$ citric acid content in optimum of pressing temperature $\left(200^{\circ} \mathrm{C}\right)$ and time $(10 \mathrm{~min})$; phenol formaldehyde $(\mathrm{PF})$ is particleboard bonded with $12 \mathrm{wt} \% \mathrm{PF}$ resin with the pressing condition of $200^{\circ} \mathrm{C}$ for $6 \mathrm{~min}$; polymeric $4,4^{\prime}$-methylenediphenyl isocyanate (pMDI) is particleboard bonded with $8 \mathrm{wt} \%$ pMDI with the pressing condition of $180^{\circ} \mathrm{C}$ for $8 \mathrm{~min}$; control is sugi (Cryptomeria japonica) wood specimen properties against termite. In a previous study, Indrayani et al. [33] also mentioned that the chemical composition of CA in MDF may act as an effective inhibitor against termite. Moreover, Papadopoulos et al. [34] found that wood modified with carboxylic acid anhydrides, such as acetic acid anhydride, showed the greatest resistance against termite.

The mass losses of specimens during the 12-week fungal decay tests are also presented in Table 2. The mass losses of the boards bonded with CA exposed to the brown-rot fungus were quite similar to those of boards bonded with PF and pMDI. However, the mass losses of boards bonded with $\mathrm{CA}$ and exposed to the white-rot fungus were higher than those of boards bonded with PF. On the other hand, they were lower than those of the board bonded with pMDI. In addition, the degree of mass losses of boards bonded with CA was much lower than that of solid wood specimens (Cryptomeria japonica). In a previous study, Despot et al. [35] demonstrated that wood modified by CA had the greatest protection against decay. They also mentioned that the enhancement of decay resistance in wood modified by CA was exclusively the result of the cross-linking of CA and hydroxyl groups of the wood components. Therefore, the boards had good resistance against decay.

Based on the results of this study, boards bonded with CA manufactured at effective conditions of hot pressing had some advantages: i.e., good bending, IB strength, dimensional stability, biological durability comparable to synthetic resin, and low formaldehyde emission. However, they also had low WB properties and SH power. Considering the industrial conditions of pressing temperature and time of particleboard manufacturing (i.e., $140-180^{\circ} \mathrm{C}$ and 5-7 min, respectively), boards bonded with $\mathrm{CA}$ require high-pressing temperature and long pressing time. Therefore, improvement of SH power and reductions of pressing temperature and time will be investigated in future research.

\section{Changes of chemical structure}

Changes in chemical structure of the boards bonded with CA manufactured at several pressing temperatures and times were measured by FTIR. The results are shown in Figs. 8 and 9. Particles collected from the particleboard were divided into two conditions as follows: (I) original particleboard specimen and (II) particleboard specimens after cyclic aging treatment to remove unreacted CA.

Figure 8I shows that an absorption peak definitely appeared at approximately $1721 \mathrm{~cm}^{-1}$ in the board manufactured at $140^{\circ} \mathrm{C}$ (b) to $220^{\circ} \mathrm{C}$ (f). This peak is basically assigned to $\mathrm{C}=\mathrm{O}$ stretching derived from the carboxyl group and/or the $\mathrm{C}=\mathrm{O}$ ester group [36, 37]. However, the peak decreased with increasing pressing temperature from $140^{\circ} \mathrm{C}$ (b) to $220^{\circ} \mathrm{C}$ (f). A small shoulder peak was also recognized around $1200 \mathrm{~cm}^{-1}$. This peak is ascribed to C-O stretching of formed ester bonds [38-41]. Conversely, in Fig. 8II, the absorbance intensity of the peak at approximately $1721 \mathrm{~cm}^{-1}$ increased with increasing pressing temperature. Furthermore, the absorbance intensity of the peaks at around $1721 \mathrm{~cm}^{-1}$ of the board manufactured at $140^{\circ} \mathrm{C} \mathrm{(b)} \mathrm{and} 160^{\circ} \mathrm{C} \mathrm{(c)} \mathrm{after} \mathrm{boiling} \mathrm{treatment} \mathrm{(Fig.} \mathrm{8II)}$ was lower than that of boards before boiling treatment (Fig. 8I).

Table 3 shows that the $\mathrm{pH}$ values of the boards manufactured at low temperature were lower than those of boards manufactured at high temperature. This means that the unreacted CA from the boards manufactured at low temperature was largely released into the water after the boiling treatment. Because of that, the peaks of the boards manufactured at low temperature decreased after boiling treatment. Considering that the melting point and boiling point of $\mathrm{CA}$ are about 150 and $170{ }^{\circ} \mathrm{C}$, respectively, CA reacted effectively with the hydroxyl group of sweet sorghum bagasse at high temperature. Based on those results, 


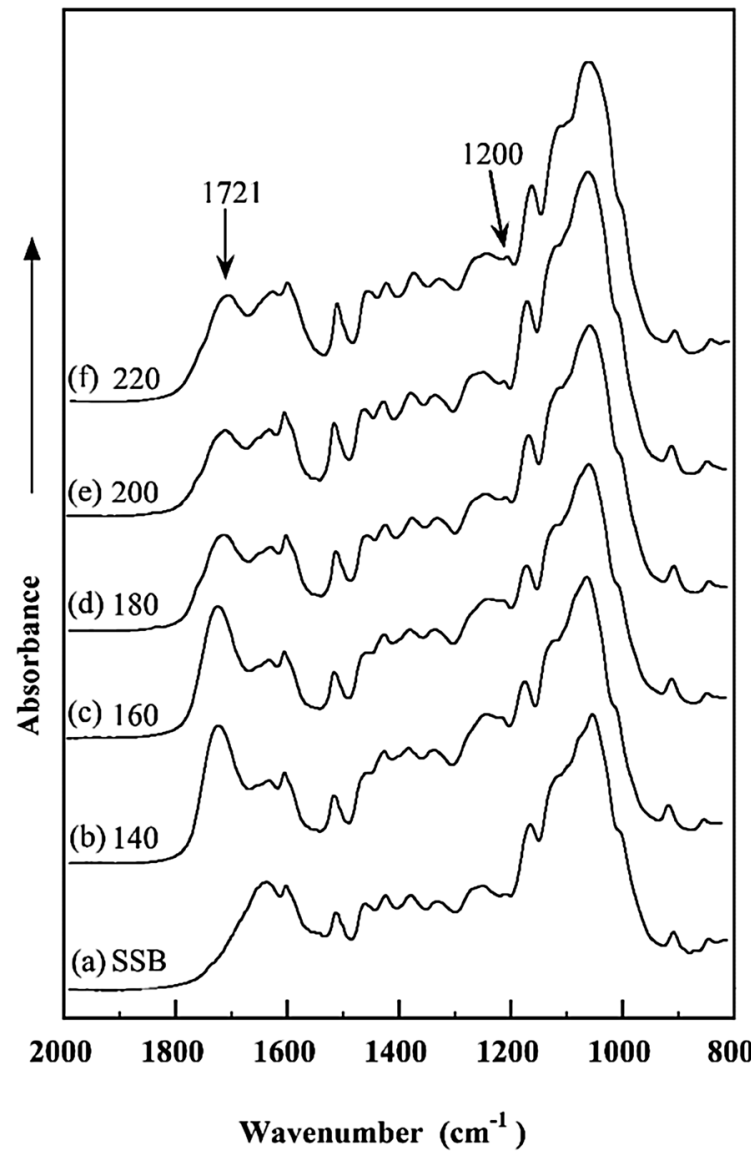

(I)

Fig. 8 Fourier transform infrared spectra of original particle of sweet sorghum bagasse (SSB) (a), sweet sorghum bagasse particleboard bonded with $20 \mathrm{wt} \%$ citric acid under pressing temperature of 140

we conclude that the low physical properties of the boards manufactured at low temperature would be affected by the low reactivity of CA.

The absorbance intensity of the peaks at around $1721 \mathrm{~cm}^{-1}$ decreased with increasing pressing time, as shown in Fig. 9I. However, those peaks increased with increasing pressing time, as shown in Fig. 9II. The small peak at around $1200 \mathrm{~cm}^{-1}$ can also be observed in the figures. From Fig. 9I, II, the peaks at around $1721 \mathrm{~cm}^{-1}$ of specimen (b) and (c) were decreased after boiling treatment. In Table 3, the $\mathrm{pH}$ of boards manufactured at short pressing time was lower than that of boards manufactured at long pressing time. Consequently, the unreacted CA of the boards manufactured at short pressing time would release into the water under boiling treatment. This means that the boards manufactured at short pressing time contained an abundance of unreacted CA. These results support the low physical properties found for the boards manufactured at short pressing time.

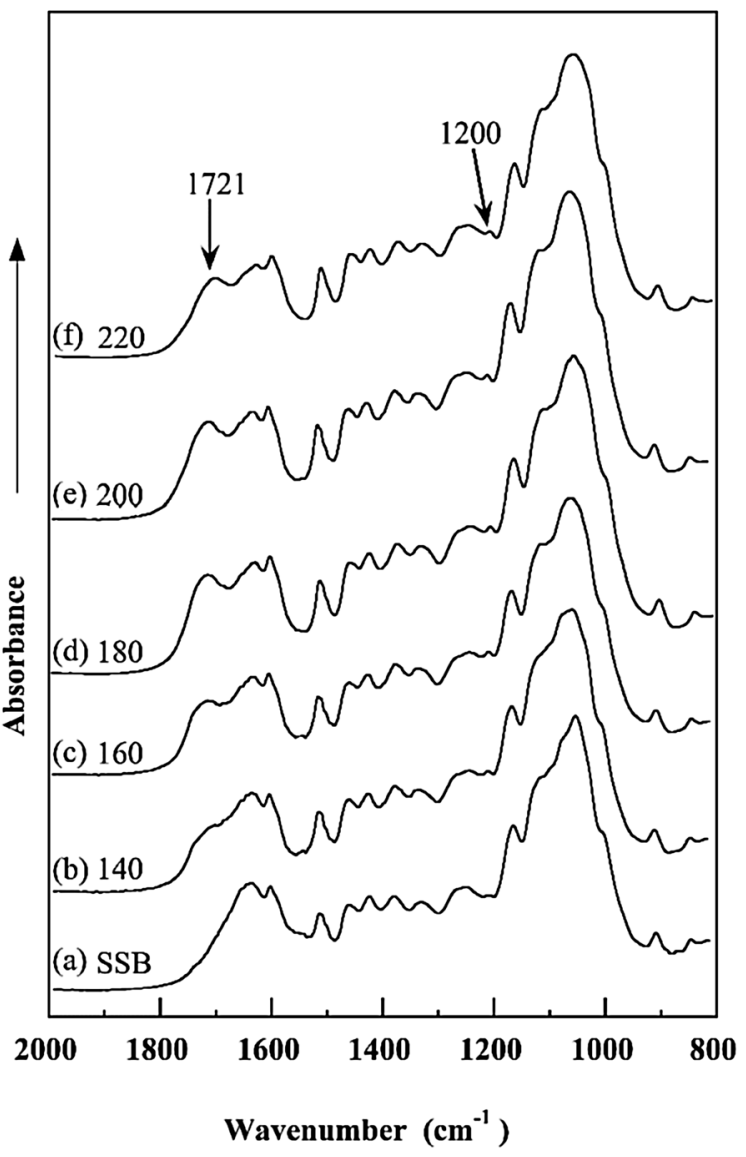

(II) (b), $160(c), 180(d), 200(e)$, and $220(f){ }^{\circ} \mathrm{C}$ before (I) and after (II) cyclic aging treatment

According to the FTIR results in both Figs. 8 and 9, high and long pressing temperature and time, respectively, were necessary to produce an effective reaction of CA with sweet sorghum bagasse particles.

\section{Conclusions}

The effects of the pressing temperature and time on the physical properties of sweet sorghum bagasse particleboard bonded with CA were investigated. The physical properties of CA boards improved with increasing pressing temperature from 140 to $200^{\circ} \mathrm{C}$, and decreased at $220^{\circ} \mathrm{C}$ under pressing time of $10 \mathrm{~min}$. Furthermore, the physical properties also increased when pressing time increased from 2 to $10 \mathrm{~min}$, and decreased at $15 \mathrm{~min}$ under pressing temperature of $200^{\circ} \mathrm{C}$. Thus, effective pressing temperature and time were $200^{\circ} \mathrm{C}$ and $10 \mathrm{~min}$, respectively. The dry-MOR, IB strength, and TS of 


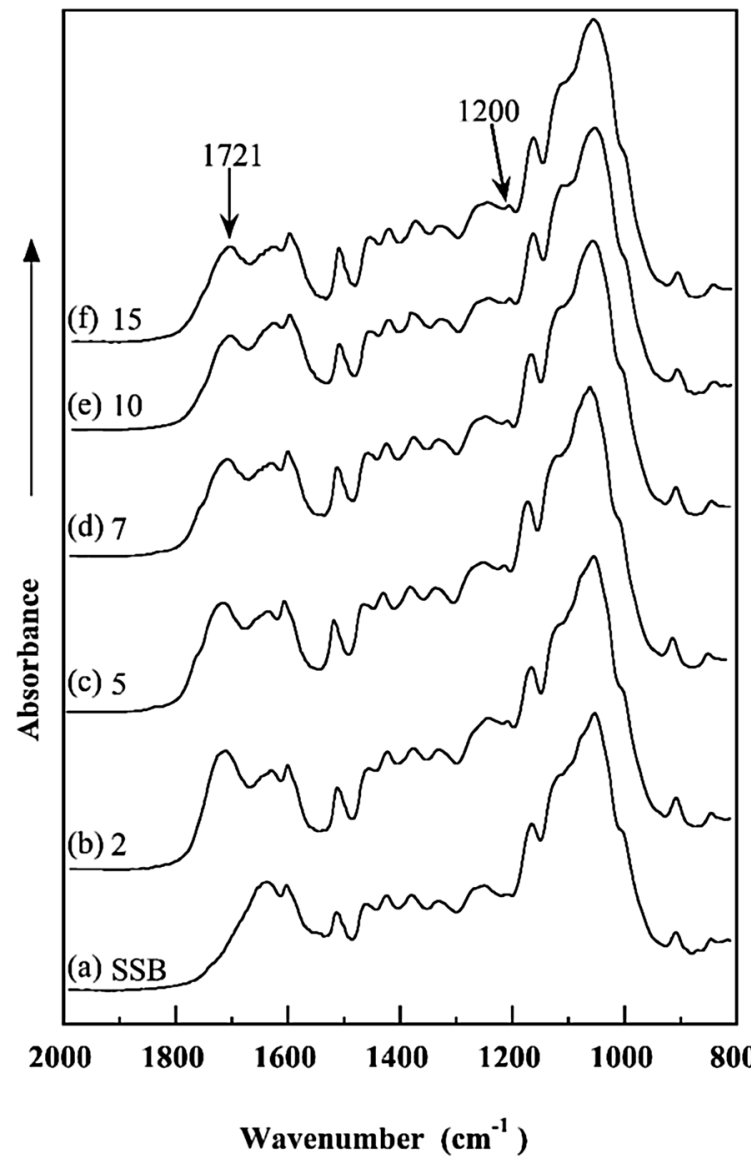

(I)

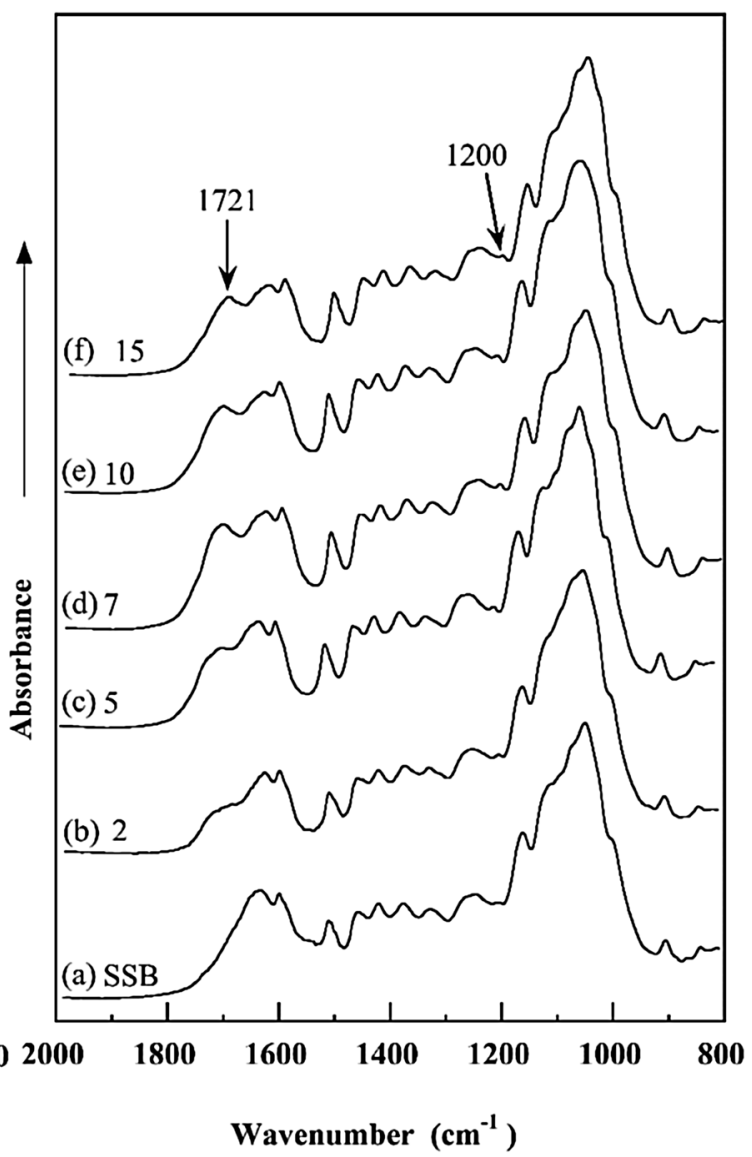

(II)

Fig. 9 Fourier transform infrared spectra of original particle of sweet sorghum bagasse $(a)$, sweet sorghum bagasse particleboard bonded with $20 \mathrm{wt} \%$ citric acid (CA) under pressing times of $2(b), 5(c), 7(d), 10(e)$, and $15(f)$ minutes before $(\mathbf{I})$ and after (II) cyclic aging treatment

Table $3 \mathrm{pH}$ value of the water after TS test of particleboard bonded with citric acid

\begin{tabular}{|c|c|c|c|c|c|c|c|c|c|c|}
\hline & \multicolumn{10}{|c|}{ Type of particle board } \\
\hline & \multicolumn{5}{|c|}{ Based on pressing temperature } & \multicolumn{5}{|c|}{ Based on pressing time } \\
\hline & CA140 & CA160 & CA180 & CA200 & CA220 & $\mathrm{CA} 2$ & CA5 & CA7 & CA10 & CA15 \\
\hline $\mathrm{pH}$ & $2.83(0.01)$ & $2.91(0.02)$ & $3.31(0.06)$ & $4.48(0.04)$ & $5.51(0.10)$ & $3.05(0.05)$ & $3.88(0.19)$ & $4.27(0.24)$ & $4.48(0.04)$ & $5.104(0.08)$ \\
\hline
\end{tabular}

Values in parentheses are standard deviation

Citric acid (CA) is particleboard bonded with $20 \mathrm{wt} \%$ citric acid content; 140, 160, 180, 200, and 220 are pressing temperature; 2, 5, 7, 10, 15 are pressing time; thickness swelling (TS) is swelling of thickness of particleboard after imersion of sample in the $20^{\circ} \mathrm{C}$ of water for $24 \mathrm{~h}$

boards manufactured under effective conditions of hot pressing satisfied the type 18 requirements of JIS A 5908 [19]. In addition, the Wet-MOR and SH power of boards satisfied type 13 and 8 of JIS A 5908, respectively. However, the wet-MOR and SH power of CA boards were lower than those of boards bonded using $\mathrm{PF}$ resin and pMDI. The boards bonded with CA had low formaldehyde emission, and effective biological durability against termite and fungus attack. Based on the infrared spectra, ester linkages appeared clearly in boards manufactured at $200^{\circ} \mathrm{C}$ and $10 \mathrm{~min}$. This means that those were the effective conditions under which the reaction between hydroxyl groups of sweet sorghum bagasse and carboxyl group of CA was activated to form ester linkages. As a result, characterization of particleboard was clarified. 
Acknowledgements The authors would like to thank the Science and Technology Research Partnership for Sustainable Development (SATREPS) and Sakigake-Kyoto University for financial support of the study, the Indonesian Institute of Sciences (LIPI) for supplying raw materials, and Oshika Co., Ltd. for supplying adhesives.

\section{References}

1. FAO (2009) State of the world's forests: global demand for wood product. Science New York Society, New York

2. FAO (2015) Forest product statictic: 2014 global forest products: facts and figures. Forest Economic, Policy and product Division, FAO Forest Department, Rome

3. Nath DC, Mwchahary DD (2012) Population increase and deforestation: a study in Kokrajhar district of Assam, India. Int J Sci Res Publ 20:1-12

4. FAS (2016) World agricultural production. In: United States Dep. Agric. http://apps.fas.usda.gov/psdonline/circulars/production.pdf. Accessed 6 Oct 2016

5. Theerarattananoon K, Xu F, Wilson J, Ballard R, Mckinney L, Staggenborg S, Vadlani P, Pei Zj, Wang D (2011) Physical properties of pellets made from sorghum stalk, corn stover, wheat straw, and big bluestem. Ind Crops Prod 33:325-332

6. Linden JC, Henk LL, Murphy VG, Smith DH, Gabrielsen BC, Tangerdy RP, Czako L (1987) Preservation of potential fermentables in sweet sorghum by ensiling. Biotechnol Bioeng 30:860-867

7. Pizzi A (2006) Recent developments in eco-efficient bio-based adhesives for wood bonding: opportunities and issues. J Adhes Sci Technol 20:829-846

8. Kojima Y, Ishino A, Kobori H, Suzuki S, Ito H, Makise R, Huguchi I, Okamoto M (2015) Reinforcement of wood flour board containing ligno-cellulose nanofiber made from recycled wood. J Wood Sci 61:492-499

9. Yang I, Kuo M, Myers DJ, Pu A (2006) Comparison of protein-based adhesive resins for wood composites. J Wood Sci 52:503-508

10. Mansouri N-E El, Pizzi A, Salvado J (2007) Lignin-based polycondensation resins for wood adhesives. J Appl Polym Sci 103:1690-1699

11. Krug D, Tobisch S (2010) Use of proteins as binders for woodbased panel [Einsatz von Proteinen als Bindemittel für Holzwerkstoffe]. Eur J Wood Wood Prod 68:289-301

12. Hoong YB, Paridah MT, Loh YF, Jalaludin H, Chuah LA (2011) A new source of natural adhesive: Acacia mangium bark extracts co-polymerized with phenol-formaldehyde (PF) for bonding Mempisang (Annonaceae spp.) veneers. Int $\mathbf{J}$ Adhes Adhes $31: 164-167$

13. Umemura K, Ueda T, Munawar SS, Kawai S (2012) Application of citric acid as natural adhesive for wood. J Appl Polym Sci 123:1991-1996

14. Umemura K, Sugihara O, Kawai S (2013) Investigation of a new natural adhesive composed of citric acid and sucrose for particleboard. J Wood Sci 59:203-208

15. Umemura K, Sugihara O, Kawai S (2014) Investigation of a new natural adhesive composed of citric acid and sucrose for particleboard II: effects of board density and pressing temperature. J Wood Sci 61:40-44

16. Widyorini R, Umemura K, Isnan R, Putra DR, Awaludin A, Prayitno TA (2016) Manufacture and properties of citric acidbonded particleboard made from bamboo materials. Eur J Wood Wood Prod 74:57-65
17. Liao R, Xu J, Umemura K (2016) Low density sugarcane bagasse particleboard bonded and additive content. BioResources 11:2174-2185

18. Kusumah SS, Umemura K, Yoshioka K, Miyafuji H, Kanayama K (2016) Utilization of sweet sorghum bagasse and citric acid for manufacturing of particleboard I: effects of pre-drying treatment and citric acid content on the board properties. Ind Crop Prod 84:34-42

19. JIS A 5908 (2003) Particleboard (in Japanase). Japanese Standards Association, Tokyo, p 451

20. Japan Wood Preserving Association (JWPA) (2001) JWPA JWPSTW- P 1. Introduction of wood preservation (in Japanese). JWPA, Tokyo

21. JIS K 1571 (2004) Test methods for determining the effectiveness of wood preservatives and their performance requirements (in English). Japanese Standards Association, Tokyo, pp 1-37

22. JIS A 1460 (2001) Building boards. Determination of formaldehyde emission-desiccator method (in Japanese). Japanese Standards Association, Tokyo, p 258

23. Yang F, Fei B, Wu Z, Peng L, yu Y (2014) Selected properties of corrugated particleboards made from bamboo waste (Phyllostachys edulis) laminated with medium-density fiberboard panels. BioResources 9:1085-1096

24. Yang H, Yan R, Chen H, Lee DH, Zheng C (2007) Characteristics of hemicellulose, cellulose and lignin pyrolysis. Fuel 86:1781-1788

25. Barbooti MM, Al-Sammerrai DA (1986) Thermal decomposition of citric acid. Thermochim Acta 98:119-126

26. Azeredo HMC, Kontou-Vrettou C, Moates GK, Wellner N, Cross K, Pereira PHF, Waldron KW (2015) Wheat straw hemicellulose films as affected by citric acid. Food Hydrocoll 50:1-6

27. Roffael E, Rauch W (1972) Production of particleboards using sulfite black liquor as binder. III. Possibilitiies of shortening the post-thermal treatment for sulfite liquor bonded particleboards of $9 \mathrm{~mm}$ thickness. Holzforschung 26:197-202

28. Umemura K, Ueda T, Kawai S (2012) Effects of moulding temperature on the physical properties of wood-based moulding bonded with citric acid. For Prod J 62:63-68

29. Xu X, Yao F, Wu Q, Zhou D (2009) The influence of wax-sizing on dimension stability and mechanical properties of bagasse particleboard. Ind Crops Prod 29:80-85

30. Hosseinaei O, Wang S, Enayati AA, Rials TG (2012) Effects of hemicellulose extraction on properties of wood flour and woodplastic composites. Compos Part A Appl Sci Manuf 43:686-694

31. Feng X, Xiao Z, Sui S, Wang Q, Xie Y (2014) Esterification of wood with citric acid: The catalytic effects of sodium hypophosphite (SHP). Holzforschung 68:427-433

32. Gambhir ML, Jamwal N (2014) Building and construction material: testing and quality control. McGraw Hill, India

33. Indrayani Y, Setyawati D, Munawar SS, Umemura K, Yoshimura $\mathrm{T}$ (2015) Evaluation of termite resistance of medium density fiberboard (MDF) Manufacture from agricultural fiber bonded with citric acid. Procedia. Environ Sci 28:778-782

34. Papadopoulos AN, Avtzis DN, Avtzis ND (2008) The biological effectiveness of wood modified with linear chain carboxylic acid anhydrides against the subterranean termites Reticulitermes flavipes. Holz als Roh - und Werkst 66:249-252

35. Despot R, Hasan M, Jug M (2008) Biological durability of wood modified by citric acid. Drv Ind 59:55-59

36. Yang CQ, Xu Y, Wang D (1996) FT-IR spectroscopy study of the polycarboxylic acids used for paper wet strength improvement. Ind Eng Chem Res 35:4037-4042

37. Žagar E, Grdadolnik J (2003) An infrared spectroscopic study of H-bond network in hyperbranched polyester polyol. J Mol Struct 658:143-152 
38. Hassan ML, Rowell RM, Fadl NA, Yacoub SF, Christainsen AW (2000) Thermoplasticization of bagasse. I. Preparation and characterization of esterified bagasse fibers. J Appl Polym Sci 76:561-574

39. Bagheri L, Yarmand M, Madadlou A, Mousavi ME (2014) Transglutaminase-induced or citric acid-mediated cross-linking of whey proteins to tune the characteristics of subsequently desolvated sub-micron and nano-scaled particles. J Microencapsul $31: 636-643$
40. Groen H, Roberts KJ (2001) Nucleation, growth, and pseudopolymorphic behavior of citric acid as monitored in situ by attenuated total reflection fourier transform infrared spectroscopy. Society 10723-10730

41. Rhim J, Park H, Lee C, Jun J, Kim D LY (2004) Crosslinked poly(vinyl alcohol) membranes containing sulfonic acid group: proton and methanol transport through membranes. J Memb Sci 238:143-151 